\title{
LA "COMUNIDAD" Y SUS ARTICULACIONES. APORTES PARA PENSAR EL CONCEPTO DE "COMUNIDAD" EN PUEL MAPU (PATAGONIA ARGENTINA)
}

Mapuche "Community" and its Articulations. Contributions to Think about the Concept of "Community" in Puel Mapu (Patagonia, Argentina).

\section{HERNÁN HORACIO SCHIAFFINI*}

Fecha de recepción: 10 de marzo de 2017 - Fecha de aprobación: 03 de abril de 2017

\section{Resumen}

A partir de un hecho que funciona como ilustración y disparador, discutimos el concepto de "comunidad" tomando como referencia a la población rural mapuche de Río Negro y Chubut, en la Patagonia argentina actual.

Analizamos las formas en que la sociología y la antropología han abordado la cuestión y cómo se expresaron estas perspectivas en ciertos estudios antropológicos empíricos. Describimos las características actuales de las "comunidades" mapuche e indagamos en algunos aspectos históricos que intervinieron en su conformación. Finalmente, proponemos un modelo para su análisis.

Planteamos como hipótesis que la actual "comunidad" mapuche en la Patagonia argentina surge como una entidad sobredeterminada y constituye un significante flotante que articula diferentes dimensiones de la reproducción social de quienes son definidos como sus miembros en ese mismo proceso.

Nos basamos en registros etnográficos desde 2009 hasta la actualidad.

Palabras clave: comunidad, mapuche, sobredeterminación, significante flotante

\section{Abstract}

From a fact that functions as illustration and trigger, we discuss the concept of "community" taking as reference the rural population Mapuche of Río Negro and Chubut, in present-day Argentine Patagonia.

We analyze the ways in which sociology and anthropology have addressed the issue and how these perspectives were expressed in empirical anthropological studies. We describe the current characteristics of Mapuche "communities" and investigate in some historical aspects that intervened in their conformation. Finally, we propose a model for its analysis.

We hypothesize that the current Mapuche "community" in Argentine Patagonia emerges as an overdetermined entity and constitutes a floating signifier that articulates different dimensions of the social reproduction of those defined as their members in the same process.

We rely on ethnographic records from 2009 to the present.

Keywords: community; mapuche, overdetermination, floating signifier

\footnotetext{
* Doctor en Antropología. Investigador Asistente de CONICET, Universidad Nacional de la Patagonia San Juan Bosco. Sede Esquel, Chubut, Argentina. Artículo enmarcado en Proyecto interno de trabajo de CONICET "El trabajo y la confrontación. Determinaciones sociales de la producción económica en familias mapuche de Chubut y Río Negro". Corro-e: hernanschiaffini@ comahue-conicet.gob.ar, hernanschiaffini@gmail.com
} 


\section{Introducción}

Iniciaremos con la narrativa de un hecho que hemos presentado en trabajos anteriores (2011, 2014) pero de los que intentaremos una interpretación nueva hacia el final de este texto.

Hacia 2004 una crecida del río Chubut, en la provincia homónima en la Patagonia argentina, dejó muy deteriorada la pasarela que permitía a los habitantes de la comunidad mapuche Vuelta del Río unir las márgenes de ese curso de agua ${ }^{1}$.

Las crecidas del Chubut son habituales y suelen generar percances de distintas magnitudes. Esta vez el problema era grave: la pasarela, situada junto al centro de salud, era el acceso más importante al paraje. Para colmo, la mayoría de los pobladores vivían y viven "del otro lado del río". Cruzar era y es una necesidad cotidiana para llegar a los centros urbanos más cercanos, El Maitén, El Bolsón, Lago Puelo o Esquel.

La pasarela derrumbada era una estructura de hierro y madera sostenida por tensores metálicos. Permitía el paso de personas caminando o a caballo y el tránsito de ganado, pero era demasiado estrecha para automóviles, camionetas o camiones. Cuando por algún motivo un automotor debía ingresar a la localidad (por ejemplo cuando una ambulancia del Hospital de El Maitén debía atender alguna emergencia) debía hacerlo por caminos alternativos, más largos y menos seguros. Algunos son solamente huellas marcadas sobre la tierra.

Años después, Vialidad Provincial de Chubut ofreció la construcción de un puente sobre el río para reemplazar la caída pasarela. Estaría ubicado en el mismo lugar en que se encon- traba aquella, pero sería de concreto y permitiría la entrada de automóviles y camiones.

Los pobladores de Vuelta del Río se reunieron a discutir la propuesta. Algunas personas la apoyaban, pero otras se manifestaron en contra. Las dudas aparecían: "si nadie en la comunidad tiene camiones ¿para qué un puente tan grande?". "En la comunidad nadie tiene camiones ni tantos animales, ni se necesita un puente tan grande" (entrevistas en terreno, julio de 2010). Lo que inmediatamente se sospechó es que, en realidad, la necesidad de un puente con las características propuestas estaba en intereses externos. "No es un puente para que nosotros salgamos, sino para que ellos entren". "No tienen tanto entusiasmo para construir las casas de la gente, pero para hacer ese puente sí" (entrevistas en terreno, Julio de 2010).

Cuando comenzamos a registrar estos sucesos, tiempo después de las inundaciones que habían derribado la pasarela pero antes de la propuesta de su reemplazo, Vuelta del Río había tenido un conflicto con un ganadero no mapuche de El Maitén quien, en arreglo con un miembro de la comunidad, quería introducir animales en el territorio. El problema es que pocos años antes ese mismo ganadero había pedido el desalojo de otra familia de Vuelta del Río, desalojo que se produjo brutalmente, donde los policías actuantes derribaron la casa de las víctimas ${ }^{2}$. Por esta razón la mayor parte de la comunidad se opuso a negociar con este individuo y le negaron la entrada en los campos. "Si hubiera estado el puente, a ése no lo sacábamos más", me dijo uno de los participantes de estos eventos, pensando en las facilidades que hubiera tenido para entrar "de facto". 
Finalmente se construyó una nueva pasarela, mejor y más ancha que la anterior, por la que puede pasar (ajustadamente) un automóvil, pero no una camioneta ni un camión.

De esta manera una pasarela estrecha sirvió a las necesidades de los pobladores de Vuelta del Río sin que tuvieran que resignar el control del tránsito hacia el interior de su propio espacio territorial.

El caso nos presenta multitud de preguntas, pero algunas queremos discutirlas aquí. Evidentemente procesos como éstos imbrican distintos tipos de acciones de orden colectivo. ¿Cómo se conforma la entidad "comunitaria" que protagoniza estos hechos? ¿Cuál es el proceso mediante el cual decisiones tomadas pasan a ser decisiones "de la comunidad"? ¿Cómo entender los intereses cruzados y las disputas internas en torno de estos acontecimientos? ¿Cómo puede entenderse la unidad de lo "comunitario" mapuche en el marco de intereses particulares divergentes? Sintéticamente: ¿qué es una "comunidad" mapuche en el contexto actual en la Patagonia argentina?

\section{Preguntas en torno de la "comunidad"}

La espesura de la noción de "comunidad" se hace presente al nombrarla. Sin embargo es habitual su utilización acrítica, ignorando las densidades conceptuales subyacentes que conlleva. Este uso no problematizado permite, en el ámbito del sentido común, la aplicación de dicha categoría a distintos grupos de pertenencia.

Minorías políticas, poblaciones migrantes, defensores de la diversidad de género o diferentes colectividades de origen extranjero aparecen nombradas como "comunidades". En especial los pueblos originarios son sujetos a esta denominación. Y en muchos casos las propias personas que se sienten parte de estos espacios adoptan dicha expresión para referirse a su propio grupo.

En este texto queremos dedicarnos al análisis del concepto de "comunidad", pero tomando como referencia a las actuales "comunidades" mapuche de la Patagonia argentina, con foco en las provincias de Río Negro y Chubut.

En la Patagonia argentina rural la palabra "comunidad" designa, cuando hablamos del pueblo mapuche y su actualidad un espacio que es, por lo menos, político, parental, territorial, ritual y económico.

"Comunidad" es la forma predominante a través de la que se categoriza a las unidades poblacionales mapuche en esta zona desde el Estado y la sociedad civil. Otras formas como "reserva" parecen, a pesar de su estatus legal reconocido, ir cayendo paulatinamente en desuso.

Sin embargo, la unidad del término no es en absoluto expresión de unidad de lo que designa. Bajo el rótulo "comunidad" se engloban características, situaciones, procesos y posicionamientos muy diferentes.

Queremos, entonces preguntarnos ¿qué es una "comunidad" mapuche? ¿Cómo se la ha concebido desde distintas perspectivas sociológicas y antropológicas? ¿Son suficientes esas elaboraciones? ¿O debemos repensar y reformular ciertas nociones?

Para adelantar nuestras hipótesis diremos que, efectivamente, es posible proponer una 
mirada que entienda a la "comunidad" no solo como un proceso social, no solo como un grupo de pertenencia, no solo como un conjunto de prácticas y representaciones sino específicamente como un significante y, particularmente, como un significante que articula procesos complejos y diversos y adquiere sentido a partir de las tensiones que se desarrollan en su interior: un significante flotante. Queremos entender cómo la articulación de distintas prácticas genera las condiciones de emergencia de un espacio sobredeterminado que llamamos "comunidad mapuche".

Aquí ilustraremos esta cuestión a través del eje empírico del caso que recién hemos presentado. Podríamos presentar muchos más, similares y distintos, cada uno con sus peculiaridades, surgidos de distintas localidades y contextos. Trabajamos en el área, intensivamente, desde 2009 y conocemos y habitamos la región desde mediados de la década de 1990. No lo haremos por cuestiones de espacio.

Pero no planteamos respuestas generales para problemáticas globales. No sabemos si nuestra propuesta puede aplicarse a todo el mundo mapuche. Por ello nos restringimos al caso puntual, con la sospecha de ser representativo de otros conjuntos de situaciones y como un paso de un trabajo que lleva algunos años pero tiene mucho por delante aún.

Nuestra propuesta debe ser fundamentada con precaución. Por tanto vamos a 1) describir algunas características actuales de la población mapuche de Río Negro y Chubut; 2) revisar parte de la literatura sociológica y antropológica respecto de la noción de "comunidad" y evaluar algunos de sus efectos sobre la comprensión de la "comunidad" mapuche; 3) reseñar breve- mente los procesos históricos que han llevado a la presente configuración político-territorial de la "comunidad" en la Patagonia argentina; 4) presentar y fundamentar nuestra propuesta al respecto.

\section{Características y contexto de las actuales "comunidades" rurales mapuche en Puel Mapu}

La población mapuche de la Argentina identificada por Censo Nacional de 2010 es de 205.009 personas. Siguiendo estimaciones previas, como las de la Encuesta Complementaria de Pueblos Indígenas (ECPI) de 2004-2005, entre un 75 y un $80 \%$ de ellas vive en distintos centros urbanos.

El 20 o $25 \%$ restante, el que nos interesa en este trabajo, reside aún en el campo, atravesando complejas y periódicas tramas de migraciones. Y la mayoría de esas personas vive, además, en "comunidades", agrupamientos dispersos de algunas decenas de familias, cuyos hogares se hallan a veces a varios kilómetros de distancia el uno del otro y donde crían cabras y ovejas en terrenos pobres en pastos y en agua ${ }^{3}$.

Esta situación es el fruto de densas trayectorias históricas y especialmente de la abrupta disrupción producida en el mundo mapuche por las llamadas "Campañas al Desierto": procesos de expropiación territorial y política que incluyen un genocidio y que extienden sus consecuencias después de casi ciento cincuenta años de producidos. La "comunidad" como hoy se nos presenta no es la "forma natural" de organización del pueblo mapuche sino el resultado de procesos sociales pasados y actuales. 
Las "comunidades" se hallan organizadas políticamente en distintos grados; asentadas en territorio que suele carecer de reconocimiento legal, o que conjuga simultáneamente diversos tipos de propiedad (privada, fiscal o colectiva); con estatus jurídicos variables (algunas tienen personería jurídica en tanto Asociación Civil, nacional o provincial, otras cuentan con personerías indígenas entregadas por el Instituto Nacional de Asuntos Indígenas -INAI-, otras no tienen reconocimiento estatal formal); atravesando conflictos de distinto tipo: internos, externos, económicos, territoriales, contra particulares, contra el Estado.

Algunas "comunidades" han construido alianzas con organizaciones 0 partidos políticos y con agencias gubernamentales e intentan obtener mínimas ventajas de esos vínculos: respaldo para sus reclamos, inclusión en proyectos y subsidios, obtención de mejoras para sus hogares o tanques australianos para los campos. A veces algunos integrantes, sin que necesariamente los demás los avalen, establecen otros vínculos -con el Estado o con particulares- que les permiten capitalizar individualmente situaciones particulares y así desatan conflictos internos, como veíamos al inicio. Así como existe diversidad en las actitudes y posiciones al interior de las comunidades, también existe diversidad en las elecciones y estrategias que cada una sostiene. Los posicionamientos de las "comunidades" se perfilan, en este sentido, como fenómenos contingentes.

\section{La "comunidad" perdida. Conceptualiza- ciones clásicas en torno de la "comunidad"}

La elaboración del concepto de "comunidad", contrapuesto al de "sociedad", constituye uno de los ejes del surgimiento de la sociología clásica. Giddens (1994) indicaba que la problemática del cambio social y la disolución de las "sociedades tradicionales" se encontraba en los fundamentos de dichas reflexiones. Al respecto también Wolf (1999) señaló el peso de dichos procesos en el surgimiento de las ciencias sociales y la división del trabajo intelectual de fines del siglo XIX.

\begin{abstract}
"Hemos visto cómo la sociología brotó de un esfuerzo por contrarrestar el desorden social creando para ello una teoría del orden social, situando el orden y el desorden en la cantidad y calidad de las relaciones sociales. Consecuencia importante de este enfoque es que nace en una polaridad entre dos tipos de sociedad: una en que el orden social es maximizado porque las relaciones sociales están apretadamente entretejidas y cubiertas con el consenso del valor; y otro en que el desorden social predomina sobre el orden porque las relaciones sociales están atomizadas y trastornadas porque hay disentimiento en cuanto a los valores. Hay tan solo un paso entre inferir esta polaridad y considerar el proceso social como un cambio de un tipo de sociedad a otro. Esto pareció muy congruente con la opinión general de que la vida moderna lleva en sí una desintegración progresiva de los modos de vida que fueron la marca distintiva de los "buenos y viejos tiempos" de nuestros mayores" (Wolf, 1999: 24).
\end{abstract}

Mientras que en la antropología clásica evolucionista fue, entre otros, Morgan (1971) [1877] quien expresó esta tensión al proponer el uso de las categorías de societae y civitae para oponer la sociedad gentilicia a la sociedad estatal (Llinares García, 1997), fueron originalmente Marx (2009) [1853], Weber (2002) [1922], Durkheim (1987) [1893] y Tönnies (1947) [1887] quienes se refirieron, con énfasis diversos, a lo que hoy denominaríamos la cuestión de la "comunidad". 
No podemos aquí desarrollar en su extensión todas sus ideas por motivos de espacio; remitimos a textos como el de Álvaro (2013) o de Marinis (2005) para una discusión más detallada. Sin embargo, introduciremos la distinción entre Gemeinschaft y Gesellschaft elaborada por Tönnies (1947) [1887] y algunas otras distinciones clásicas a modo de ejemplo y como hilo conductor de nuestras interpretaciones.

Manuel Delgado (2005) analizó la teoría de Tönnies con detalle. En dicha teoría comunidad y sociedad no son objetos, sino formas de la voluntad. La Gemeinschaft remite a una vinculación humana anclada en los orígenes comunes, el parentesco y una voluntad orgánica. La Gesellschaft remite al mundo de la acción racional, el contrato y la aplicación de medios afines. El Estado burgués es un buen exponente de la Gesellschaft, la sociedad del contrato y la burocracia racional. La Gemeinschaft, en cambio, se expresa en relaciones familiares, de confianza. Ambas categorías, sin embargo, coexisten a pesar de que puedan subordinarse, según el caso, la una a la otra.

"La Gemeinschaft es esa sociedad imaginada como natural, que se caracteriza por el papel central que en ella juega el parentesco y la vecindad, sus miembros se conocen y confían mutuamente entre sí, comparten vida cotidiana y trabajo y desarrollan su actividad teniendo como fondo un paisaje al que aman. La existencia de la Gemeinschaft se asocia íntimamente con un territorio con delimitaciones claras, cuyos habitantes "naturales" ordenan sus experiencias a partir de valores divinamente inspirados y/o legitimados por la tradición y la historia. Todo en la noción de Gemeinschaft parece responder a la evocación nostálgica de un tipo de vinculación social basada en la verdad, una manera de convivialidad anterior, que tendría como presupuesto la voluntad esencial de sus componentes (Wesenwille), cohesionados por una experiencia común del pasado y organizando unitariamente su conciencia" (Delgado, 2005: 41).

\section{En cambio la Gesellschaft:}

"se funda en la voluntad arbitraria de sus miembros (Kürwille). Estos comparten más el futuro que el pasado, subordinan los sentimientos a la razón, calculan medios y fines y actúan en función de ellos. En Tönnies el modelo de la primera es la solidaridad que se da entre un organismo vivo y sus funciones. El de la segunda es la máquina, el agregado mecánico, el artilugio construido" (Idem: 42).

La distinción entre Gemeinschaft y Gesellchaft provee rápidamente, como es fácil intuir, una serie de dicotomías que, presentes o no en la propuesta original de Tönnies (para Tönnies estos conceptos son tipos ideales que siempre aparecen entremezclados, y no categorías empíricas), parecen de fácil traslado al análisis de poblaciones rurales pequeñas: éstas serían "comunidades" basadas en relaciones tipo Gemeinschaft, ancladas en el parentesco y la tradición. Y serían muy diferentes de las poblaciones "modernas" urbanas, basadas en el paradigma del contrato y la racionalidad instrumental al estilo Gesellschaft.

En Marx, como revelan -entre otros textossus publicaciones en periódicos norteamericanos $^{4}$, era constante el análisis de la penetración de los Estados capitalistas y las grandes casas de comercio sobre los territorios de China, India y África. También de cómo las poblaciones "pre-capitalistas" resultaban transformadas y desarticuladas producto de ese contacto. Por ejemplo:

\footnotetext{
"Estas pequeñas formas estereotipadas de organismo social [las "comunidades" locales] han sido destruidas en su mayor parte y están desapareciendo, no tanto por culpa de la brutal intromisión del recaudador británico de contribuciones o del soldado británico, como por la acción del vapor inglés y de la libertad de comercio inglesa. Estas comunidades de tipo familiar tenían
} 
por base la industria doméstica, esa combinación particular de tejido a mano, hilado a mano y laboreo a mano, que les permitía bastarse a sí mismas. La intromisión inglesa, que colocó al hilador en Lancashire y al tejedor en Bengala, o que barrió tanto al hilador hindú como al tejedor hindú, disolvió esas pequeñas comunidades semibárbaras y semicivilizadas, al hacer saltar su base económica, produciendo así la más grande y, para decir la verdad, la única revolución social que jamás se ha visto en Asia. (Marx; 2009: 24). [La aclaración es nuestra].

Weber (1922) desarrolló, a la par de los conceptos de "acción racional" con arreglo a fines o a valores, sobre las "acciones afectivas" y las "tradicionales" y teorizó acerca las formas de autoridad "tradicional" y "carismática" cuyo sustento se hallaba en la persona del señor y la confianza en el caudillo, respectivamente.

Según Álvaro (2013), Weber sigue el clima de la época al plantear una oposición abierta entre las comunidades "tradicionales" y las relaciones que propone el mercado:

\begin{abstract}
"Ni siquiera es necesario interpretar a partir de lo no-dicho puesto que Weber, por una vez, lo dice abiertamente, sin rodeos ni evasivas: la Gemeinschaft de carácter personal es portadora de relaciones humanas originarias, obligaciones vinculantes de fraternidad y piedad, $y$, dado que siempre supone confraternidad, no puede más que oponerse a las relaciones impersonales propias del mercado capitalista" (Álvaro, 2013: 236).
\end{abstract}

Para Durkheim [1893], por su parte, la distinción entre solidaridad mecánica y solidaridad orgánica se vinculaba con el profundo proceso de individuación que atravesaban las sociedades del centro de Europa.

"La sociedad no es vista bajo el mismo aspecto en los dos casos. En el primero [solidaridad mecánica], lo que denominamos así es un conjunto más o menos orga- nizado de creencias y sentimientos comunes a todos los demás miembros del grupo: es el tipo colectivo. Por el contrario, la sociedad, de la que en el segundo caso somos solidarios [dont nous sommes solidaires], es un sistema de funciones diferentes y especiales unido por relaciones definidas" (Durkheim en Giddens 1994: 143).

Sin embargo, a diferencia por ejemplo de Tönnies, rechazaba la idea de una "falta de moralidad" en la sociedad moderna, hecho negativo que quizá podría atribuirse a ese proceso de individuación.

"Sin razón se opone la sociedad que deriva de la comunidad de creencias a la que tiene por base la cooperación, otorgando a la primera solo un carácter moral y viendo en la segunda solo un agrupamiento económico. En realidad, también la cooperación tiene su moralidad intrínseca" (Idem: 144-145).

Como vemos, las elaboraciones de Durkheim se separan de las que había previamente propuesto Tönnies, y aquí acordamos con Delgado (2005) en que no deben asimilarse los conceptos de solidaridad mecánica y orgánica con los Gemeinschaft y Gesellschaft respectivamente.

Todas estas perspectivas teóricas no son, por cierto, comparables ni asimilables así sin más. Cada una parte y partía de supuestos epistemológicos y filosóficos diferentes que difícilmente se puedan articular de manera armónica. A pesar de ello revelan un cierto espíritu de época, una incomodidad que las nacientes ciencias sociales estaban comenzando a procesar.

A la vez, constituyen el sustrato conceptual de las elaboraciones con que la antropología abordará a las "comunidades" indígenas africanas, asiáticas y americanas a partir de las primeras décadas del siglo XX. 


\section{La "comunidad" y la antropología ${ }^{5}$}

El pensamiento clásico se expresó en las distintas corrientes antropológicas. La distinción entre solidaridad mecánica y orgánica, de origen durkhemiano, se manifestó en la antropología funcionalista y estructural-funcionalista británica y delimitó formas específicas de pensar las unidades sociales y políticas indígenas en términos de totalidades funcionales, como en la obra de Malinowski (1986) [1922] o como asociaciones de segmentos, según Evans-Pritchard y Fortes (2010) [1941].

Esta influencia durkhemiana llegó a América Latina a través de antropólogos formados en la Escuela de Chicago, donde Radcliffe-Brown fue profesor durante tres años (Medina Hernández, 2000) en la década de 1930. Sol Tax, uno de estos discípulos formados en el estructural-funcionalismo, trabajó en México y Guatemala durante las décadas de 1930 y 1940 y participó de la formación de algunos de los primeros antropólogos profesionales de México. Por supuesto, como también señala Medina Hernández (Ibid.), la recepción de estas influencias en el medio mexicano adoptó características muy particulares ${ }^{6}$.

Con respecto al mundo mapuche, los trabajos de Louis Faron en Chile (1997) [1964] se basaron en una perspectiva estructural-funcionalista que guardaba similitudes con las propuestas de los autores mencionados. Su mirada se acercaba desde posturas durkhemianas, con énfasis en el estudio de las estructuras sociales y morales. Faron se expresaba sobre las reducciones mapuche de la siguiente manera, articulando los conceptos de linaje y congregación ritual con las ideas de totalidad y segmentalidad:
"Las reducciones son, por un lado, creaciones de un gobierno extraño, pero por el otro lado, ahora que han existido en ellas varias generaciones, son de hecho entidades sociales mapuches. Sin embargo, en todo caso, la reducción siempre es un segmento de una entidad más grande que es la congregación ritual" (Faron; 1997: 48) [El destacado es nuestro].

Por otro lado, las elaboraciones de Tönnies que mencionamos, junto a la influencia de Dilthey y Kant sobre Boas (Delgado, 2005) se trasladaron también no solo a los culturalistas norteamericanos sino también, mediante la persona de Robert Redfield, a los primeros trabajos antropológicos mexicanos.

Los "estudios de comunidad" tienen una larga trayectoria en la antropología mexicana. Los trabajos de Redfield (1947) en Tepoztlán y luego en la península de Yucatán en torno del continum folk/urbano toman como eje el modelo de Tönnies para pensar las voluntades comunitarias.

Dentro de estas perspectivas la "comunidad" aparece como una entidad cerrada en sí misma, ${ }^{7}$ una micrototalidad acabada, relativamente autorregulada, que se enfrenta a los cambios y transformaciones que le impone la sociedad general desde una posición subordinada y cuya sentencia de muerte o disolución parece estar, sin embargo, firmada de antemano.

En esta línea encontramos trabajos en toda América Latina pero, para señalar algunos, citamos la obra de Frank Cancian (1976) en México. También podemos volver a mencionar los trabajos de Redfield (1947) en torno del continum "folk/urbano" y los "estudios de comunidad" de Sol Tax (1941) mediante la metodología de la "action-anthropology". 
Las transformaciones sociales, políticas y disciplinarias acontecidas a partir de la década de 1960 permitieron comenzar a evaluar a la "comunidad" desde otros puntos de vista. El avance del marxismo en la academia, las polémicas entre "campesinistas" y "descampesinistas" y la relectura de los estudios rurales rusos en la línea de Chayanov abrieron nuevas perspectivas.

Un nuevo polo analítico puso el énfasis en señalar cómo los distintos procesos históricos y sociales atravesados por las poblaciones indígenas habrían determinado las formas actuales de sus instituciones. Podemos mencionar un trabajo emblemático de Chance y Taylor (1987) en esta perspectiva, enfocado en una temática clásica de la antropología mexicana: los sistemas de cargos. Y también la compilación de Leopoldo Bartolomé, Procesos de articulación social (1977), con análisis de casos de toda América Latina, como ejemplos más cercanos de esta perspectiva, donde los factores "externos" a la "comunidad" juegan un importante papel en su constitución misma y donde la tensión no está puesta entre el "afuera" o el "adentro" de la "comunidad" sino en el peso que tienen los "sujetos" versus el "sistema".

Aquí ya no es una "comunidad perdida" la protagonista de los análisis, sino que comienza a percibirse la posibilidad de que las "comunidades" sean efectivamente re-creadas por diversos procesos. Las "comunidades" ya no serían, entonces, (o no son hoy en día) una unidad esencial que se degrada, sino una construcción contemporánea cuyos fundamentos son otros procesos sociales que, de manera más o menos enmascarada, la tienen como su producto.
Las luchas por la autonomía, la autodeterminación y el reconocimiento de los pueblos indígenas situaron en una nueva perspectiva el debate en torno de la "comunidad". En nuestros días el antropólogo Miguel Lisbona Guillén (2005) reflotó estos debates, incluyéndolos en la reflexión de la filosofía política, al igual que Héctor Díaz Polanco (2007). Díaz-Polanco, quien en otro importante texto (2006) abordó el tema contra las posiciones de liberales y comunitaristas, hizo también evidente el peso de la historia en la producción de las "comunidades".

"En efecto, uno de los resultados más notables del proceso colonial fue la recreación de la comunidad como núcleo cultural en el que encontraron abrigo las nuevas y múltiples identidades conformadas a lo largo de tres siglos [...].

Así, pues, la organización socioétnica se simplificó: las entidades étnicas, antes organizadas en complejas y jerárquicas estructuras supracomunales en Mesoamérica, en los Andes y entre los mayas de las tierras bajas, se trasformaron en un archipiélago de comunidades, aisladas entre sí o con relaciones muy discretas, y cada una de ellas fue colocada frente al poder del Estado. En suma, la territorialidad e identidad de las etnias indígenas, al menos las reconocidas, se redujeron a la comunidad, bajo la forma de pueblos-cabeceras y sus sujetos" (Díaz-Polanco, 2007: 21-21).

En suma, en este breve recorrido parecemos asistir a un cambio de eje en las perspectivas de análisis de la "comunidad". De un conjunto de nociones que interpretaban a las "comunidades" como expresiones cercanas al modelo de la Gemeinschaft pasamos no hacia un modelo tipo Gesellschaft, sino hacia la comprensión de cómo distintos procesos históricos, económicos y 
políticos son en realidad factores causales en la producción de las "comunidades". Las aldeas, los agrupamientos, las reducciones no son el origen de la evolución histórica de tal o cual sociedad, sino su punto de llegada en la actualidad. Así la Gemeinschaft se revela no como origen, sino como artificio. No como causa, sino como efecto. La "comunidad" no es el espacio esencial desde el que emanan procesos divergentes, sino el producto de una articulación de variables sociales que se nos hace necesario comprender y analizar.

\section{“Comunalidad” y "comunalización”}

Dentro de aquellos trabajos que conciben a la "comunidad" como un efecto o una manifestación de otros procesos antes que como una realidad que se reproduce a sí misma, algunos revisaron aquellos elementos que hacen a la constitución de un "sentido de colectividad". Dicho sentido involucra las afectividades y la construcción de sentimientos de pertenencia que se elaboran y legitiman de muy variadas formas.

El antropólogo mixe Floriberto Díaz Gómez (2007) se refirió al espíritu de la "comunalidad" al reflexionar en torno a la construcción "india" de la "comunidad". La "comunalidad" sería "el aspecto inmanente de la comunidad", constituido por la articulación de lo "comunal", lo "colectivo", lo "complementario" y lo "integral". Aquí la "comunidad" surge de la intersección de estos elementos y puede graficarse a través de fórmulas como la siguiente:

La Tierra como madre y como territorio.

El consenso en asamblea para la toma de decisiones.

El servicio gratuito como ejercicio de autoridad.

El trabajo colectivo como un acto de recreación.

Los ritos y ceremonias como expresión del don comunal.

(Díaz Gómez, 2007: 40).
James Brow (1990), por su parte, desarrolló el concepto de "proceso de comunalización" como una forma de construcción de la pertenencia que interpela al sujeto desde su constitución misma, haciendo parte en una "primordialización" que naturaliza los elementos fundamentales a través de los que se elabora la "identidad". Habría, según Brow, patrones de acción que tienden a construir un "estar juntos" y que pueden implicar reconstrucciones históricas, resignificación de lazos y apropiaciones, renovaciones o rechazos de elementos "tradicionales", lo que denomina "usos del pasado". La "comunidad", en este sentido, sería un momento más o menos cristalizado dentro de interminables procesos de "comunalización".

\section{En Argentina}

En Argentina las influencias del culturalismo boasiano o el estructural-funcionalismo al estilo de Parsons o Radcliffe-Brown tuvieron escasa y nula influencia en el momento de profesionalización e inserción académica de la antropología. Como señalaban Neufeld y Wallace refiriéndose a la Universidad de Buenos Aires:

\footnotetext{
Esa antropología oficial no estuvo vinculada, ni a la antropología social inglesa, ni a los durkheimianos franceses, ni al culturalismo norteamericano. Sí, en cambio, a posiciones teórico-políticas propias de la Argentina posterior a 1930. Sus principales representantes -Imbelloni, Vivante, Martínez Soler, Bórmida, Menghin- se consideraban adherentes de la "escuela histórico-cultural" o Escuela de Viena. Su propósito fundamental era reconstruir los "patrimonios" en estado puro, no contaminado, de los pueblos americanos. No los conmovió el etnocidio: no se trataba más que de pueblo objeto, pueblos etnográficos. (Neufeld y Wallace; 1999: 53).
} 
La "comunidad" no era aquí un objeto de estudio específico, sino que se enfocaban, en muchos casos, en el registro de la "cultura material" y su articulación con el repertorio mitológico "original" de tal o cual pueblo. Importaba recuperar ese pasado supuestamente prístino, no entender las determinaciones de su presente.

Por fortuna estas perspectivas se vieron superadas en las décadas siguientes ${ }^{8}$. Si bien existían ya trabajos como los de Ratier (1971, 1972) que examinaban las interconexiones entre comunidades rurales, villas, grandes centros urbanos y peronismo, en los años que siguieron la "antropología oficial" adquirió nuevas perspectivas.

En la producción antropológica actual podríamos englobar los trabajos de Balazote y Radovich (1995), Briones (2002), Valverde (2009), Valverde y García (2007), Ramos (2010), Crespo y Tozzini (2013) dentro un campo común donde, pese a sus diferencias, se contemplan los procesos históricos y las interconexiones que atraviesan a las poblaciones mapuche sin que la "comunidad" sea necesariamente el centro de sus reflexiones. Estos trabajos han revelado, entre otras cosas, las relaciones de los mapuche con el mercado y su rol subordinado como reservas de fuerza de trabajo, el lugar que ocupan en las distintas construcciones de "aboriginalidad" propuestas por el Estado, las disputas en torno del "patrimonio" y las estrategias de defensa y reconstrucción del territorio.

Actualmente también otros trabajos, como los de Cañuqueo (2015) y Cañuqueo, Kropff y Perez (2015) enfocan los procesos de constitución de "comunidades" en la Patagonia como parte de procesos de lucha y reorganización política y territorial, atravesados por la acción del Estado.

\section{De la producción de la "comunidad" mapuche. Expropiación, genocidio y resistencias}

De acuerdo a lo dicho es necesario comprender a la "comunidad" mapuche actual como el resultado, siempre en movimiento, de diversos procesos históricos. Vamos a ser muy breves en este punto y remitiremos a otros trabajos especializados que han analizado con detalle los procesos previos y posteriores a las llamadas "Campañas al Desierto" que el Estado argentino inició hacia $1879^{9}$.

Sin querer adelantarnos a la propia lógica de la exposición, podemos decir que el análisis histórico pone rápidamente en evidencia el carácter múltiplemente determinado de la "comunidad". No es, decíamos antes, la "forma natural" de organización de los mapuche, sino el producto de los procesos que atravesaron.

Brevemente y obviando -solo en este momento y por razones de espacio- los cambios atravesados por las unidades políticas y sociales mapuche en el extenso período de contacto con la Corona española, podemos señalar que la producción de la actual "comunidad" mapuche se constituye a través de, al menos, tres procesos conectados: 1) su expropiación territorial y política, 2) su administración estatal y capitalista, 3) las estrategias y resistencias elaboradas por la población mapuche. 
1) La expropiación territorial y política del pueblo mapuche requirió de un genocidio. En Argentina se llamó a este proceso "Campañas al Desierto" y en Chile "Pacificación de la Araucanía". La inserción de estos países en el mercado mundial de fines del siglo XIX les requería, por un lado, la expansión sobre las tierras controladas por los mapuche; por el otro, su constitución como Estados burgueses modernos. El surgimiento de la matriz Estado-Nación-Territorio propuesta por Bechis (2010) explica las ramificaciones políticas y legales de estos procesos desde la perspectiva del Estado.

Esta etapa no implica solamente la derrota militar de los contingentes indígenas, sino lo que Marín (1995) llamó -pensando en otros contextos- realización de la victoria: la ocupación efectiva del territorio obtenido y la aceptación generalizada de los valores y representaciones de los vencedores por parte del resto de la población.

En términos concretos la avanzada militar significó la desarticulación militar y política de las unidades mapuche. Lofche, rewe y butalmapu sufrieron profundos procesos de desintegración al ser atacados sus medios de reproducción, sus territorios y rastrilladas, sus alianzas políticas y sus propios cuerpos. De acuerdo con lo que Lenton (1999) denominaba "destribalización”, se inicia así el proceso de destrucción de su autonomía.

\section{2)}

"En términos comparativos, el estado argentino no habría producido una política sistemática, continuada y coherente de incorporación de la población originaria de Patagonia al estado-nación luego de finalizadas las campañas militares. Las radicaciones y entregas de tierras a indígenas aparecerían, entonces, como un conjunto de respuestas espasmódicas que no formarían parte de una política de estado continua y comprensiva" (Briones y Delrio, 2002: 45).

Estas "respuestas espasmódicas" forman parte de una serie de procesos de administración del territorio y las poblaciones víctimas de la "Campaña al Desierto". La realización de la victoria, la "destribalización" y la administración estatal y capitalista de los contingentes mapuche víctima de la violencia militar se ligan y se superponen.

El momento de ocupación estatal efectiva del territorio, posterior lógica y cronológicamente a la victoria militar, se vincula a la apropiación privada de la tierra, la aparición del latifundio y de variados personajes relacionados al comercio que, en muchos casos, se harán de grandes extensiones de territorio endeudando a los mapuche sobrevivientes.

\begin{abstract}
"A partir de ese momento [el final de las campañas militares] el gobierno aplicó diferentes políticas de radicación de los indígenas que se pueden agrupar en tres tipos: la propiedad individual, la ocupación precaria de tierras fiscales y la creación de colonias colectivas" (Kropff, 2005: 268)
\end{abstract}

Pero esto reformula no solamente los espacios territoriales que ocuparán las "reservas" que se reconstruyan, sino también el rol de los líderes y la organización interna de las unidades políticas.

"Las negociaciones con el estado para obtener tierras para asentarse implicaron la reestructuración de las relaciones políticas en función de articularse en torno a un cacique referente que fuera reconocido como interlocutor por el estado. Estas rearticulaciones se producían en lugares de confinamiento (muchos de ellos ubicados en los márgenes del Río 
Negro) donde se reunían las familias desplazadas por la avanzada militar. Del resultado de esas negociaciones -que se producían en una trama de relaciones atravesada por políticas estatales y también eclesiásticas- dependía el destino geográfico final de los caciques "y su gente" que conformarían, a partir de ese proceso, entidades políticas y sociales reconocidas por el estado" (Ídem; 2005: 268).

De tal manera, la disrupción producida por el genocidio y la ocupación territorial reformularon profundamente la configuración de las unidades políticas y sociales mapuche. Sin dudas, la actual "comunidad" es heredera de estos procesos por cuanto los re-asentamiento y la re-producción de sus liderazgos se dieron dentro de estos marcos.

3) Las resistencias y estrategias de la población mapuche para subsistir y reconstituirse acompañan incluso los procesos originales de su despojo. Pero tampoco cejan allí, sino que continúan y se extienden a lo largo de todo el siglo $X X$ y la actualidad.

Delrío (2005) mostró cómo, en términos históricos, los procesos de reterritorialización y reconstitución "comunitaria", si bien se producen en un espacio enajenado y administrado por fuera de las instituciones mapuche, no están exentos de sus propias capacidades de "agencia". Aunque no fueran una determinación predominante, las iniciativas originarias fueron necesarias y eficaces para dar forma al acceso al territorio expropiado y su organización.

La propia permanencia en el territorio y las diversas maneras en que se sostiene (que incluyen migraciones, combinación de ingresos y esfuerzos, alianzas políticas, etc.), son una evidencia de esto. En otro lugar (2011) hemos destacado cómo los propios procesos de la vida cotidiana en las "comunidades" mapuche adquieren un carácter defensivo en los actuales contextos. La persistencia de la "comunidad" depende, en buena medida, de las acciones de sus miembros, no meramente de procesos ajenos.

De tal modo, pensamos que las actuales "comunidades" toman forma históricamente, entre otras cosas, a través de la articulación de una serie de procesos autónomos y heterónomos cuyo balance contingente es necesario examinar para cada caso. Buena parte de esa dinámica se sostiene, como veremos, en la actualidad.

\section{Nuevas preguntas para la "comunidad"}

Las interpretaciones que pudieron asignar a la "comunidad" mapuche una voluntad tipo Gemeinschaft o ser expresiones prístinas de un pasado arqueológico en tiempo presente mostraron sus falencias y limitaciones. Analizar a la "comunidad" en tanto objeto de estudio, pero ignorando sus vínculos con el resto de los procesos sociales; recortarla como unidad de análisis, pero desdibujando su inserción en las relaciones sociales no hizo sino construir un objeto falaz. Llevada al extremo, esta posición nos presenta una situación de inconmensurabilidad respecto de la "comunidad" $y$ el resto del mundo. Para nuestro ejemplo inicial, el rechazo a la construcción de un puente podría responder a una "voluntad de aislamiento", a un resguardo celoso de la "tradición" o a un mandato "moral-cosmológico". Pero, desde tal perspectiva, se dificultaría leerlo como un mecanismo de control de vínculos económicos, territoriales y políticos preexistentes. 
Sin embargo, en buena medida y como dijimos más arriba, el tránsito del pensamiento antropológico pasó de una mirada que concebía a la "comunidad" como una unidad autónoma y cerrada a pensarla como un objeto históricamente atravesado que mutaba en sus formas y relaciones según los tipos de vínculo que establecía con el resto de la sociedad.

Esta forma de abordar el problema abrió diversas líneas de investigación, algunas de las cuales hemos intentado reseñar más arriba.

Nuestra propia resistencia a satisfacernos con las explicaciones que brindaban estas posturas y la verificación etnográfica de que la realidad "comunitaria" mapuche desbordaba cualquiera de estas dos posiciones nos empujó a pensar una alternativa. ¿Cómo puede conceptualizarse algo que no es una "esencia", pero tampoco un mero "instrumento"? ¿Qué elemento nos permitiría explicar la articulación entre la multiplicidad de lo cotidiano y la reproducción social con la "unidad" de la identidad?

Trabajos como los de Laclau (1996), al asociar la hegemonía a la construcción de significantes, nos proveyeron una pista del camino a seguir. A partir de allí la ubicuidad del término "comunidad", que aparece en los distintos ámbitos de la economía, la política, la "espiritualidad" o el parentesco comenzó a tener, para nosotros, un nuevo sentido.

Nuestra propuesta aquí se basa en un intento por articular esas cuestiones explorando una posibilidad que no parece haber sido abordada abiertamente: la de considerar a la "comunidad" mapuche como un significante flotante, un objeto que articula hegemónicamente procesos en aparente dispersión, pero que sin embargo, constituyen el fundamento de sus propias características.

Nos interesa particularmente el concepto de sobredeterminación, elaborado por Althusser hacia 1965. Pensamos que la "comunidad" mapuche está sobredeterminada, es decir que se trata de una construcción donde se expresan simultánea y eficazmente múltiples determinaciones, surgidas de diferentes dimensiones y niveles.

La "comunidad" mapuche aparece, así, condensando en tiempo y espacio contradicciones, racionalidades y tendencias que tienen su origen, en ocasiones, en otras coordenadas de la cartografía social, pero que se integran a la "comunidad" en tanto se articulan de manera mediata o inmediata con alguna de sus dimensiones constitutivas. Por dimensiones constitutivas de la "comunidad", aquí vamos a considerar al parentesco, el trabajo, el territorio, el gobierno y la ritualidad.

Este carácter sobredeterminado de la "comunidad" hace que no podamos hallar sencillamente un "núcleo primario" de origen de las explicaciones de sus problemas. No hay un solo ámbito privilegiado de determinaciones que permita explicar todas o la mayoría de las problemáticas que presenta. Aun cuando algunas dimensiones sean ciertamente predominantes en el marco de los procesos sociales -pensamos en las relaciones de propiedad del territorio, en las dinámicas de acumulación de capital y en los vínculos políticos entre pueblo mapuche y Estado- es evidente que la "comunidad" mapuche se desenvuelve en un ámbito tan complejo y sutil que requiere de modelos multicausales, al menos en este nivel de análisis. El concepto de sobredeterminación, vale decir, se asocia directamente al de causalidad estructural. 


\section{La "comunidad", un significante flotante}

Apoyándonos, entonces, en el concepto de sobredeterminación y dando un paso más adelante, sostendremos que la "comunidad" mapuche es un significante flotante.

Ahora bien, acordamos con Laclau cuando señala que

\begin{abstract}
“...si la sistematicidad del sistema es un resultado directo del límite excluyente, es solo esta exclusión la que funda al sistema como tal. Este punto es esencial, porque de él se sigue que el sistema no puede tener un fundamento positivo y que, en consecuencia, tampoco puede significarse a sí mismo en términos de algún significado positivo" (1996: 73).
\end{abstract}

Esto no quiere decir que la "comunidad" mapuche no exista positivamente, sino que existe en tanto encarnadura de otros procesos que la toman como significante. La "comunidad" se constituye como el nudo en que se enlazan diferentes dinámicas y dimensiones que se vinculan entre sí mediante la articulación que logran gracias a su simultánea presencia/ausencia.

Esto tiene una segunda consecuencia, porque en tal sentido, podemos decir que lo "interior" o lo "exterior" a la "comunidad" mapuche recién puede distinguirse una vez que se ha constituido el significante "comunidad" como tal. No antes. Es la constitución de la "comunidad" lo que organiza o sitúa al resto de los elementos, tomándola como referencia. $Y$ tal constitución es, como veremos, un proceso dinámico, no un criterio clasificatorio estático.

Lo que es o no propio de la "comunidad" - los criterios a través de los que evalúa la pertenencia/no pertenencia, sus intereses o posicionamientos políticos y sociales- es, en realidad, parte de un proceso de articulación hegemónica. De ahí su carácter flexible y cambiante: lo propio de la "comunidad" es el resultado del balance de fuerzas de sus dimensiones constitutivas.

Ahora, ¿en qué consisten esas articulaciones? ¿Cuáles son los procesos que se vinculan para dar forma a la "comunidad"? ¿De qué manera lo hacen?

\section{La "comunidad" y la reproducción social}

La "comunidad" es, efectivamente, un objeto imaginario. Pero es un objeto imaginario que se entronca eficazmente con las cadenas de la reproducción social de las poblaciones. Es decir que es, a la vez, causa y efecto de la reproducción de las jerarquías sociales, las condiciones de vida y su propia reconstitución.

Vamos a proponer que, para reproducirse, una "comunidad" mapuche articula al menos cinco procesos que se interconectan. Estos son la filiación y la alianza, el ejercicio de la ritualidad, la producción económica, la toma colectiva de decisiones y la ocupación efectiva y defensa del territorio.

Estas cinco dimensiones de la "comunidad", que llamamos dimensiones constitutivas, son extremadamente complejas y cada una de ellas guarda, al interior, una multiplicidad notable. Las entenderemos como conjuntos de prácticas que conllevan, en cada caso, una racionalidad propia y particular y que tienen por objetivo la reproducción de un objeto específico. La filiación y la alianza resultan en la reproducción de la familia. La ritualidad en la reproducción del 
equilibro entre fuerzas (newen) humanas y no humanas. La producción económica resulta en el reinicio del ciclo ganadero y el intento de autosubsistencia. Las decisiones colectivas reproducen los balances de poder entre familias y la defensa del territorio la apropiación y el control sobre éste.

No son meros procesos lineales, sino articulaciones de redes sociales muy intrincadas. La tarea de construirlas como un objeto analítico corresponde, por supuesto, al investigador, ya que no se presentan espontáneamente en la realidad.

También es cierto que cada una de estas dimensiones tiene su historia y un desarrollo local y particular, y es necesario tenerlos en cuenta para evaluar sus características.

A la vez, se hace prontamente evidente que cada una de estas dimensiones de la reproducción comunitaria se superpone y soslaya con las demás. Es muy difícil concebir, por ejemplo, el trabajo sin remitirse al territorio, sus formas de uso y los criterios que regulan su acceso. $O$ es imposible hablar del (auto) gobierno sin referirse a los liderazgos religiosos o espirituales, a los rituales colectivos o a los antepasados.

Por tanto, consideramos a cada una de estas dimensiones como un proceso encadenado que tiene su propia lógica, su propia racionalidad, la cual no es inmediatamente intercambiable con la de las otras dimensiones. Si bien, como veremos, están conectadas, la lógica del parentesco no es, por cierto, la misma que la de la producción ganadera. La racionalidad detrás de la toma colectiva de decisiones no es la misma que rige el desempeño ritual ni la defensa del territorio.
Todas estas dimensiones resultan vinculadas y articuladas entre sí cuando el significante "comunidad" interviene sobre ellas. Pensamos que la "comunidad" es el resultado de la intersección de estas dimensiones, intersección que genera un espacio de ambigüedad e indeterminación que es "llenado" mediante dicha categoría, que adquiere así su contenido.

Por ende, los distintos procesos que participan de la reproducción social de una población determinada resultan articulados entre sí mediante la "comunidad" misma. Cuando el trabajo atraviesa al parentesco, aparece la "comunidad". Cuando el ejercicio ritual resulta cruzado por el territorio, aparece la "comunidad". Cuando para tomar una decisión colectiva hay que evaluar la presencia de distintas familias pobladoras, su acceso al territorio para pastorear animales, los lugares significativos en términos de eventos pasados o manifestaciones de los pu newen o dictámenes del ad mapu, aparece la "comunidad". Y en cada caso la "comunidad" se vacía de contenido y se vuelve a llenar de acuerdo a las urgencias y necesidades de la articulación de estas dimensiones.

De tal manera, la "comunidad" constituye el elemento que articula y asigna una identidad unificada a cada una de estas variables. Al mismo tiempo es creada a la vez que las crea como elementos comunes entre sí.

Como tal, la "comunidad" es la forma hegemónica a través de la que se reproduce la población rural mapuche de la región que hemos tomado como referencia. No es una "esencia" preexistente ni la expresión de un oportunismo instrumental: es la forma de resolver (transitoria e inacabadamente) articulaciones sociales en tensión que solo adquieren sentido al unificarse en tanto "comunitarias". 
Al revisar el caso de la pasarela de Vuelta del Río podemos observar estos entramados en acción. El caso nos sirve a modo de ilustración y no pretendemos, dadas sus peculiaridades, hacer extensivas sus dinámicas al conjunto de la población mapuche. Pero nos es útil para verificar la existencia de estas articulaciones en movimiento.

La renovación de la pasarela afectaba un bien común: el territorio y el control que el colectivo podía ejercer sobre el mismo. No interpelaba a un poblador o a dos, interpelaba a la "comunidad" como conjunto, porque existían pastos comunes que usaban todos (o muchos), zonas de aprovisionamiento de leña que abastecían al conjunto de la "comunidad", acceso al agua del río. Aunque una familia no se viera directamente afectada por el puente o por el terrateniente que quería ingresar animales a los campos, quizás un pariente sí era víctima de tal avance. A la vez, sentado el precedente y facilitada la entrada y salida de ajenos por el eventual puente ¿quién garantizaba que no fuera a pasarle a uno en el futuro?

Como se puede ver, el hecho interviene sobre una constelación de relaciones sociales. La propuesta de construcción del puente es el disparador de un entramado que afecta al menos a las dimensiones constitutivas del territorio, el trabajo, las decisiones colectivas (que en este caso se toman en Trawün, asamblea) y el parentesco. Al cruzarse la una con la otra hace su aparición en escena la "comunidad". La "comunidad" no quiere el puente.

El balance de fuerzas internas permitió cerrar el acceso al ganadero no mapuche que, asociado a otro vecino mapuche, intentaba usufructuar los campos del paraje. Para colmo, muchos de los participantes del proceso eran y son parientes directos de la familia que sufriera el desalojo por pedido de ese mismo ganadero. En este caso, claramente vinculado otra vez, a la dimensión del trabajo ganadero y al territorio, la "comunidad" se constituye como antagonista de ese miembro y su socio. La articulación de las dimensiones constitutivas "trabajo", "territorio", "decisiones colectivas" y "parentesco" condensa la "comunidad" en ese polo y obstruye su surgimiento en el otro, reduciéndolo a un mero "interés particular". Es la "comunidad" contra los "particulares".

\section{Reflexiones finales}

No basta con la aparición de solo una de las dimensiones constitutivas para crear "comunidad". El linaje por sí mismo no crea "comunidad". El ejercicio ritual por sí mismo no crea "comunidad". Es necesaria la articulación de estas dimensiones, su cruce, su solapamiento, para que tal significante emerja.

$Y$ tal solapamiento se da en aquellos lugares que hacen evidente la interdependencia de las dimensiones constitutivas. Donde el "trabajo" no solo se encuentra con el "ritual", sino donde necesita y requiere que el "ritual" se haga presente para terminar de realizarse como "trabajo". Donde lo "familiar" se entronca necesariamente con el "territorio", pues de no hacerlo correría el riesgo de dejar de existir como tal. Donde el "territorio" y el "parentesco" se hacen interdependientes de manera que la producción familiar (el "trabajo") se sostenga en tierras comunes y en la colaboración de los parientes. Allí, entonces, se generan las condiciones para la emergencia de la "comunidad" en tanto "nudo" que permite corporizar dichos procesos. 
Siguiendo este razonamiento, podríamos sostener también que el carácter de la "comunidad", (sus aspectos más visibles, sus posicionamientos y predisposiciones) estará directamente vinculado al tipo de determinaciones que intervienen sobre sus dimensiones constitutivas. En efecto, las formas en que se desarrollan o despliegan dimensiones como el trabajo, el ritual, el autogobierno, el parentesco y el territorio tendrán una influencia directa en su articulación con cada una de las demás dimensiones. Donde el "trabajo" se desarrolla mediante unidades capitalizadas, con buen número de animales (caso no muy habitual entre los mapuche de la Patagonia argentina) su articulación con el "territorio" o el "parentesco" será posiblemente distinta de aquel "trabajo" que se realiza con mano de obra familiar, apunta a la subsistencia y depende de "pastos comunes".

Lo mismo ocurre, proponemos, para el resto de las dimensiones constitutivas y su articulación. No se articula igual un "territorio" delimitado, alambrado y subsumido a la lógica de la propiedad individual que otro sostenido por el reconocimiento implícito de los vecinos y legitimado por los lazos del linaje. No se articula igual la dimensión de la "ritualidad" si es predominante el ceremonial mapuche expresado en el ad mapu, el kamarikun o el ngillatun o el ceremonial evangélico o católico y las prácticas que propone.
De esa manera podemos, quizás, interpretar parte de la diversidad de posiciones y actitudes que sostienen las "comunidades" respecto de los procesos que atraviesan. Una "comunidad" no se ve afectada por tal o cual modificación que se produzca en un supuesto "ámbito exterior" así, sin más. Sino que la hipotética modificación externa actuará sobre alguna de las dimensiones constitutivas de la "comunidad" y será necesario evaluar de qué modo dicha modificación influye sobre la articulación de esas dimensiones y la constitución del significante "comunidad".

Repetimos, no puede trazarse una analogía entre la "comunidad" y una sola de sus dimensiones constitutivas: es el producto de la articulación de todas ellas. Como tal, no es inmune a los cambios que se producen en otros puntos del mapa social, pero esos cambios no la afectan directamente sino de manera mediatizada. Las transformaciones influyen sobre las dimensiones constitutivas, y las dimensiones constitutivas se articulan en "comunidad", además de que ésta entidad posea su propia eficacia. Por eso no puede trazarse una causalidad lineal entre las transformaciones sociales generales y los cambios en la "comunidad": en medio existe el proceso de articulación que es a la vez condición y efecto de su existencia, a pesar aún de las violencias a las que está constantemente expuesta. 


\section{Notas}

1 Vuelta del Río se localiza en las márgenes de la Colonia Cushamen, en el departamento Cushamen, en el noroeste de la provincia de Chubut, a unos cien kilómetros al norte de Esquel. Se trata de una comunidad que, como muchas otras, atraviesa procesos conflictivos desde hace tiempo, con la diferencia que sostuvo y sostiene vínculos con organizaciones etno-políticas mapuche y relaciones con las agencias estatales desde una institucionalidad más consolidada que en otros casos.

${ }^{2}$ Este desalojo fue un conflicto muy visible en la provincia, al punto que implicó la destitución del Juez que lo ordenó y el juicio a los policías que intervinieron. La familia desalojada volvió a vivir en el predio en cuestión. Sin embargo, años después, el Juez fue restituido a su cargo tras ganar la apelación de su jury de enjuiciamiento por un tecnicismo y los policías, absueltos.

${ }^{3}$ Esto no quiere decir que no existan comunidades urbanas. De hecho las hay. Además, existen densos entramados que vinculan a las poblaciones "rurales" con distintas ciudades de la Patagonia. Aquí, sin embargo, nos interesan predominantemente las articulaciones sociales presentes en espacios rurales dispersos.

${ }^{4}$ Entre 1853 y 1858 Marx publicó varios artículos en el New York Daily Times donde señalaba cómo la dinámica de las relaciones sociales capitalistas irrumpía en las regiones coloniales, transformando profundamente las estructuras de poder y las formas de vida de las mismas. No abordaremos aquí, por cuestiones de espacio, otros de sus trabajos de importantes consecuencias (como el llamado

\section{Referencias bibliográficas}

Althusser L. (1983) [1965]. "Contradicción y sobredeterminación. Notas para una investigación”. En La revolución teórica de Marx. México: Siglo XXI.

Álvaro, D. (2013). El problema de la comunidad. Marx, Weber, Tönnies. Buenos Aires: Prometeo.

Balazote, A. \& Radovich, J.C. (1995). "Transiciones y fronteras agropecuarias en norpatagonia". En Hugo Trinchero (editor). Producción doméstica y capital. Estudios desde la antropología económica. Buenos Aires: Biblos.

Bartolomé, L. (1977). "Presentación”. En Procesos de articulación social. Hermitte y Bartolomé (Comp.). Buenos Aires: CLACSOAmorrurtu.

Bechis, M. (2010). Piezas de etnohistoria y antropología histórica. Buenos Aires: SAA.

Briones, C. y Delrio, W. (2002) "Patria sí, colonias también. Estrategias diferenciales de radicación de indígenas en Pampa y Patagonia (1885-1900)" En Fronteras, Ciudades y Estados. Córdoba: Alción Editora.

Brow, J. (1990). "Notas sobre comunidad, hegemonía y los usos del pasado". Anthopological Quarterly, № 63 .
Cuaderno Kovalesvky o sus notas sobre L. H. Morgan).

${ }^{5}$ El análisis pormenorizado de la transmisión y recepción del concepto de "comunidad" en la antropología latinoamericana excede nuestros límites. Aquí queremos poner en evidencia ciertas continuidades y rupturas a fines de situar apropiadamente nuestra discusión conceptual.

${ }^{6}$ El legado de la Revolución Mexicana y el peso del nacionalismo revolucionario hicieron que estas influencias se entroncaran rápidamente con una fuerte simpatía política de los antropólogos con las causas indígenas y que asumieran un rol 'comprometido' al respecto. Estas tendencias se sintetizarán, años después, en la consolidación institucional del "indigenismo" mexicano.

${ }^{7}$ De ahí también la idea de Wolf (1957) de la "comunidad corporativa cerrada". Evidentemente reformularía su mirada más adelante.

${ }^{8}$ Hablando rigurosamente, la fortuna poco tiene que ver con ello. Las corrientes teóricas hegemónicas y contra-hegemónicas suelen estar estrechamente vinculadas con los momentos políticos y sociales a los que articulan. La "escuela fenomenológica", heredera de la "histórico-cultural" en la UBA, terminó siendo desplazada de la academia de la mano de la restauración democrática de 1984.

9 Siendo ésta, 1879, la fecha "oficial" del inicio de las excursiones militares, aunque las hostilidades abarcan décadas y los años inmediatamente previos a 1879 fueron claves en el balance bélico de la zona.

Cancian, F. (1976). Economía y prestigio en una comunidad maya. El sistema religioso de cargos en Zinacantán. México: Instituto Nacional Indigenista.

Cañuqueo, L. (2015). "Tramitando comunidad indígena en Río Negro. Diálogos entre activismo, políticas de reconocimiento y cogestión". En ldentidades, №8.

Cañuqueo, L., Kropff, L. \& Pérez, P. (2015). "A la sombra del Estado. Comunalización indígena en parajes de la pre-cordillera de Río Negro, Argentina". En Revista del Museo de Antropología, №2.

Chance, J. \& Taylor, W. (1987). "Cofradías y cargos. Una perspectiva histórica de la jerarquía cívico-religiosa mesoamericana". Boletín oficial del INAH. Nueva época, №14.

Crespo, C. \& Tozzini, A. (2013). "Trayectorias de relaciones en el marco de luchas étnico - territoriales en la Patagonia Argentina”. Revista Papeles de Trabajo № 25, julio 2013. Centro de Estudios Interdisciplinarios en Etnolingüística y Antropología Socio-Cultural, Facultad de Humanidades y Artes, Universidad Nacional de Rosario. (On line, disponible en http://www.scielo.org.ar/pdf/paptra/n25/n25a01. pdf) ISSN 1852-4508.

Delgado, M. (2005). “Espacio público y comunidad. De la verdad 
comunitaria a la comunicación generalizada", dins Lisbona, M. (ed.) La comunidad a debate. Reflexiones sobre el concepto de comunidad en el México contemporáneo, Universidad de Ciencias y Artes de Chiapas.

Delrío, W. (2005). Memorias de expropiación. Sometimiento e incorporación indígena en la Patagonia, 1872-1943. Bernal: Universidad Nacional de Quilmes.

De Marinis, P. (2005). " 16 comentarios sobre la(s) sociología(s) y la(s) comunidad(es)". En Papeles del CEIC, № 15. Marzo 2005. Disponible en la web: http://www.ehu.es/CEIC/papeles/15.pdf Fac Cs Soc. Buenos Aires: UBA.

Díaz Gómez, F. (2007). "Comunidad y comunalidad". En Escrito. Comunalidad, energía viva del pensamiento mixe. México: UNAM.

Díaz-Polanco, H. (2006). Elogio de la diversidad. Globalización, multiculturalismo y etnofagia. México: Siglo XXI. (2007). La rebelión zapatista y la autonomía. México:

Siglo XXI.

Durkheim, E. (1987) [1893]. La división del trabajo social. Madrid: Akal.

Evans-Pritchard, E. \& Fortes, M. (2010) [1941]. "Introducción" en Sistemas Políticos Africanos. Fortes y Evans Pritchard (Comp.). México: CIESAS.

Faron, L. (1997) [1964]. Antupaimñamko. Moral y ritual mapuche. Santiago: Ediciones Mundo.

Giddens, A. (1994) [1971]. El capitalismo y la moderna teoría social. Barcelona: Labor.

Isla, A. (2002). Los usos políticos de la comunidad. Indigenismo y Estado. Buenos Aires: Editorial de las Ciencias.

Kropff, L. (2005). "Historia reciente de las organizaciones mapuche de la Argentina". En Movimientos sociales y derechos humanos en la Argentina. Brenda Pereyra \& Pablo Vommaro (Comp.). Buenos Aires: CICCUS.

Laclau, E. (1996). "¿Por qué los significantes vacíos son importantes para la política?". En Emancipación y diferencia. Buenos Aires: Siglo XXI.

Lenton, D. (1999). "Los dilemas de la ciudadanía y los indios argentinos. 1880-1950". En Publicar en Antropología y Ciencias Sociales, Nㅜ․

Lisbona Guillén, M. (2005). La comunidad a debate. Reflexiones sobre el concepto de comunidad en el México contemporáneo. El Colegio de Michoacán A. C.

Llinares García, M. (1997). "La búsqueda de los principios de organización de la sociedad”. En Gazeta de Antropología, Nro. 13 Disponible en http://www.gazeta-antropologia.es/?p=3518 [Consultado el 24-11-2016].

Malinowski, B. (1986) [1922]. Los argonautas del Pacífico Occidental. Buenos Aires: Planeta-Agostini.

Marín, J. C. (1995). Conversaciones sobre el poder. Una experiencia colectiva. Buenos Aires: La Rosa Blindada.
Marx, K. (2009) [1853]. "La dominación británica en la India”. En Acerca del colonialismo. Buenos Aires: Terramar ediciones.

Medina Hernández, A. (2000). En la cuatro esquinas, en el centro. Etnografía de la cosmovisión mesoamericana. México: UNAM.

Morgan, L. H. [1877] 1971. La sociedad primitiva. Madrid: Editorial Ayuso.

Neufeld, M. R. \& Wallace, S. (1999). "Antropología y Ciencias Sociales. De elaboraciones históricas, herencias no queridas y propuestas abiertas". En Antropología social y política. Hegemonía y poder: el mundo en movimiento. Neufeld et al. (Comp.). Buenos Aires: Eudeba.

Ramos, A. (2010). Los pliegues linaje. Memorias y políticas mapuche-tehuelches en contextos de desplazamiento. Buenos Aires: Eudeba.

Ratier, H. (1971). El cabecita negra. Buenos Aires: Centro Editor de América Latina.

(1972). Villeros y villas miseria. Buenos Aires.: Centro Editor de América Latina.

Redfield, R. (1947). "La sociedad folk". En Revista Mexicana de Sociología, №4.

Schiaffini, H. (2011). "En defensa de la mapu. Prácticas políticas y económicas en la construcción del territorio entre los mapuche del N. O. de Chubut". Ponencia presentada en las IV Jornadas de Jóvenes Investigadores del Instituto Gino Germani. Fac. Cs. Soc. UBA, Buenos Aires.

(2014). Los mapuche entre el alambrado y la mapu.

Poder y vida cotidiana en el noroeste rural de Chubut. Tesis doctoral inédita, FFyL, UBA.

Tax, S. (1941). "World View and Social Relations in Guatemala". En American Anthropologist, Vol. XLIII-1.

Tönnies, F. (1947) [1887]. Comunidad y sociedad. Buenos Aires: Losada.

Valverde, S. (2009). "Seríamos el espejo de lo que es Villa Pehuenia": Análisis comparativo-regional de los conflictos territoriales del pueblo mapuche en áreas turísticas de la provincia de Neuquén". En Runa, №1.

Valverde, S. \& García, A. (2007). "Políticas estatales y procesos de etnogénesis en el caso de poblaciones mapuche de Villa La Angostura, provincia de Neuquén, Argentina". En Cuadernos de Antropología Social, № 25.

Weber, M. (2002) [1922]. Economía y Sociedad. Esbozo de una sociología comprensiva. Madrid: FCE.

Wolf, E. (1981) [1957] "Comunidades corporativas cerradas de campesinos en Mesoamérica y Java Central" (Original en Southwestern Journal of Anthropology, Vol.1 3, № 1.). En Antropología Económica. Estudios etnográficos. Llobera (Comp.). Barcelona: Anagrama.

(1999). Europa y la gente sin historia. Buenos Aires: FCE. 